\title{
Correction to: Residential Mobility, Gentrification and Neighborhood Change in Spanish Cities: A Post-Crisis Perspective
}

\author{
Antonio López-Gay ${ }^{1}$ (D) Andrea Andújar-Llosa ${ }^{2}$ D $\cdot$ Luca Salvati $^{3}$
}

Published online: 2 November 2020

(c) Springer Nature Switzerland AG 2020

\section{Correction to: Spatial Demography https://doi.org/10.1007/s40980-020-00069-0}

The presentation of figures 4, 5, 6, 8 and Appendix 1 in the original publication was incorrect. The correct figures are given below (Figs. 4, 5, 6, 8).

The original article has been corrected.

The original article can be found online at https://doi.org/10.1007/s40980-020-00069-0.

Luca Salvati

luca.salvati@unimc.it

Antonio López-Gay

tlopez@ced.uab.cat

Andrea Andújar-Llosa

aandujar@us.es

1 Department of Geography, Universitat Autònoma de Barcelona \& Centre d'Estudis Demogràfics, Facultat de Lletres, Campus UAB, Barcelona, Spain

2 Department of Sociology, Universidad de Sevilla, Seville, Spain

3 Department of Economics and Law, University of Macerata, Macerata, Italy 


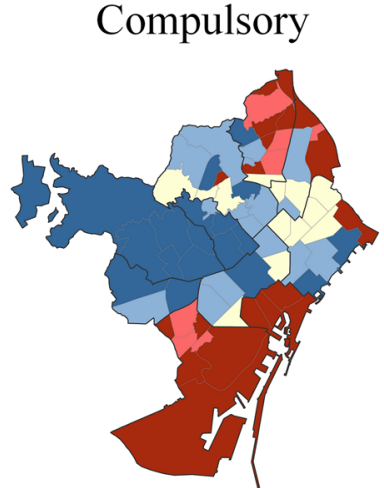

Annual avg: 19,539

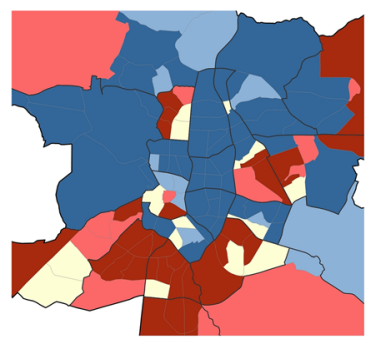

Annual avg: 40,436
Secondary

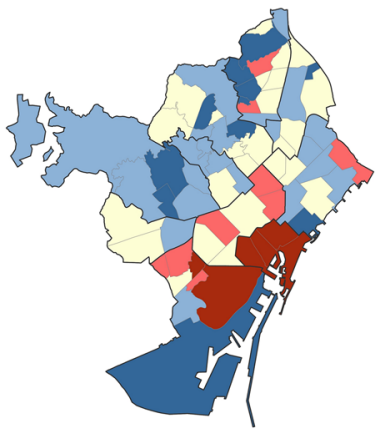

Annual avg: 13,249

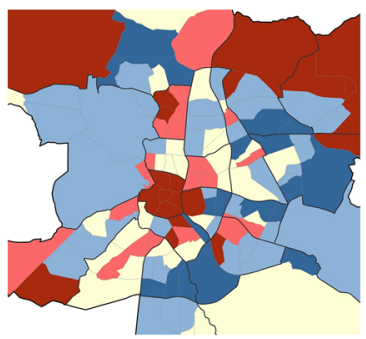

Annual avg: 20,573
University

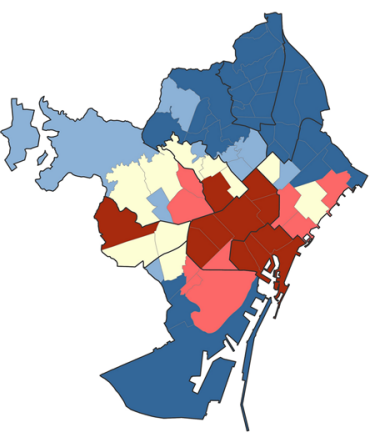

Annual avg: 33,099

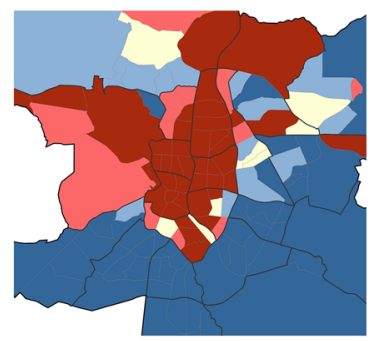

Annual avg: 49,551

Location Coefficient

$$
0,1-0,7 \square 0,7-0,9 \square 0,9-1,1 \square 1,1-1,3 \square 1,3-3,1
$$

Fig. 4 Spatial distribution of in-flows by educational attainment. Location coefficient. Population $>25$ y.o. 2015-2017. Source. Own elaboration. In-flows from the Population Register. Barcelona and Madrid city councils 


\section{Spanish born}

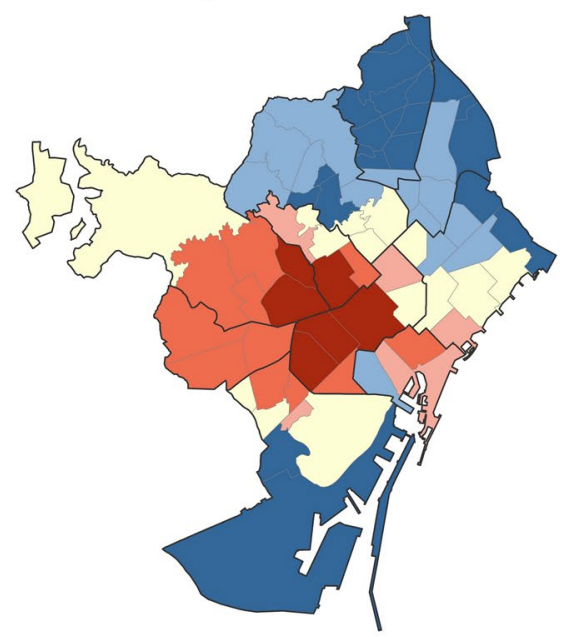

Annual avg: 10,700

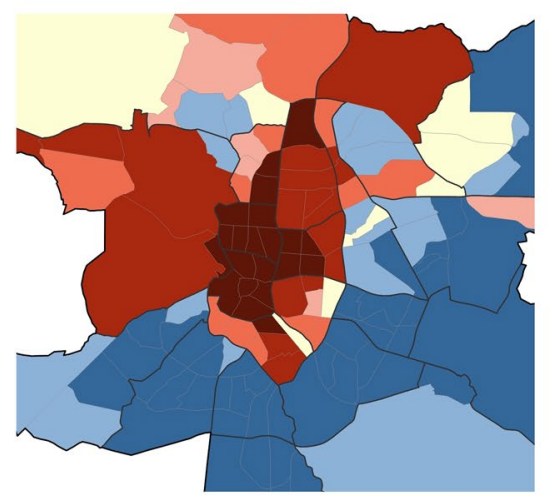

Annual avg: 27,722

\section{Foreign born}

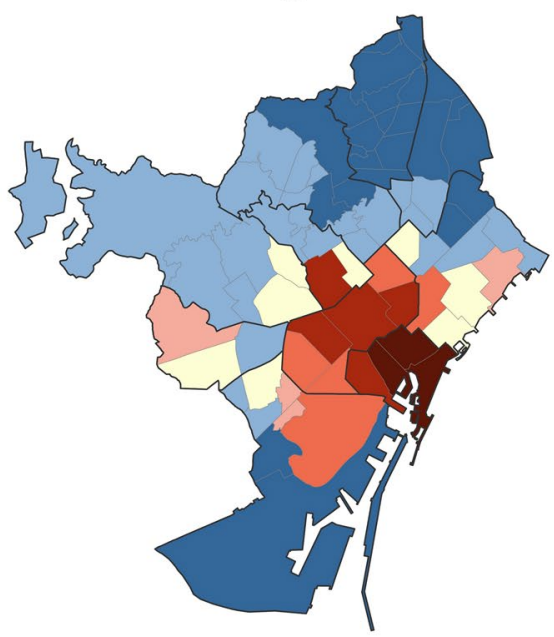

Annual avg: 22,399

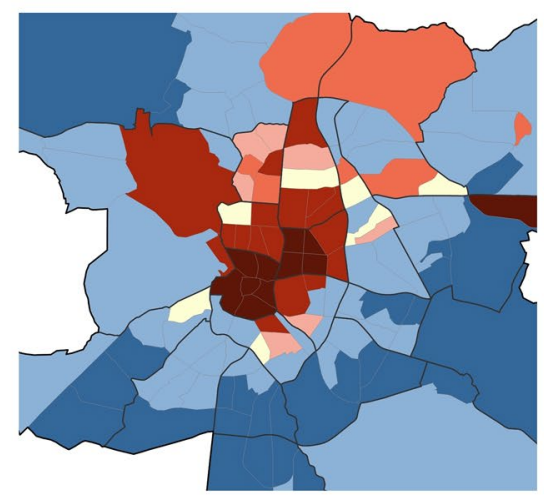

Annual avg: 21,829

\section{Location Coefficient}

$$
0,0-0,5 \square 0,5-0,9 \square 0,9-1,1 \square 1,1-1,3 \square 1,3-1,5 \square 1,5-2,0 \square 2,0-7,0
$$

Fig. 5 Spatial distribution of in-flows with university degree by birth place. Location Coefficient. Population > 25 y.o. 2015-2017. Source. Own elaboration. In-flows from the Population Register. Barcelona and Madrid city councils 


\section{Born in Europe (excluding Sp.)}

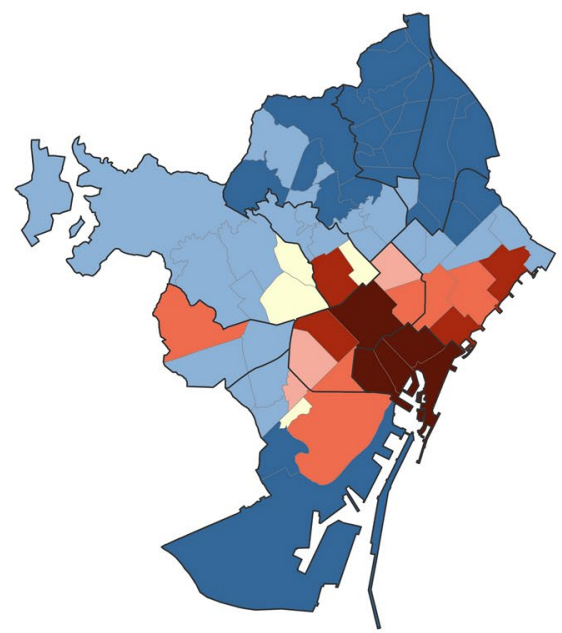

Annual avg: 7,706

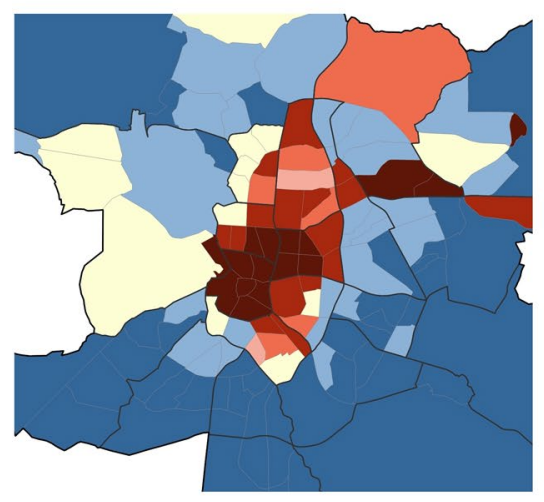

Annual avg: 4,352
Born outside Europe

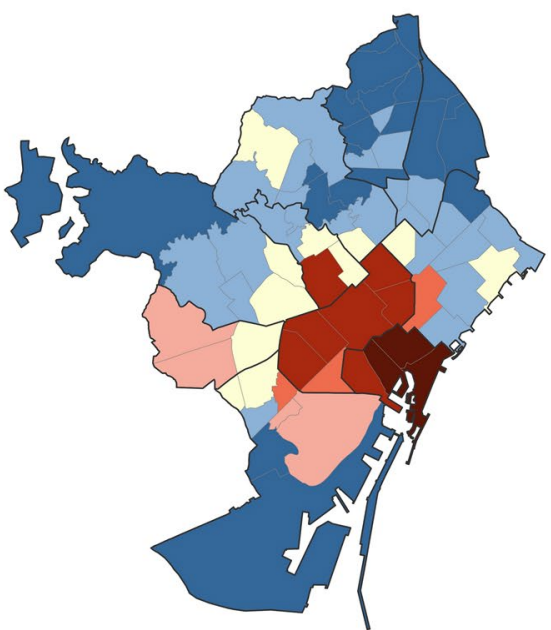

Annual avg: 14,693

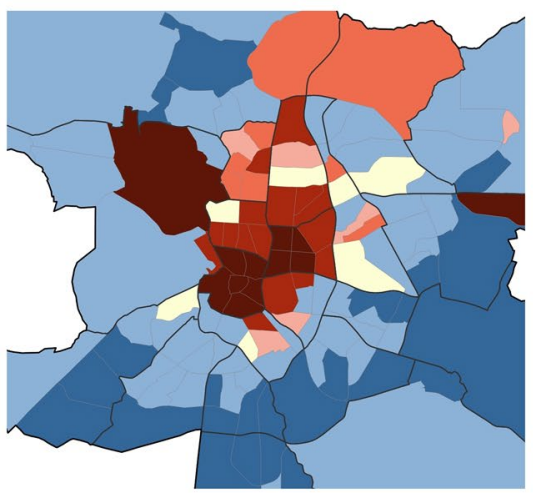

Annual avg: 17,477

\section{Location Coefficient}

$$
0,0-0,5 \square 0,5-0,9 \square 0,9-1,1 \square 1,1-1,3 \square 1,3-1,5 \square 1,5-2,0 \square 2,0-7,0
$$

Fig. 6 Spatial distribution of in-flows with university degree by birth place (foreign-born population). Location coefficient. Population > 25 y.o. 2015-2017. Source. Own elaboration. In-flows from the Population Register. Barcelona and Madrid city councils 

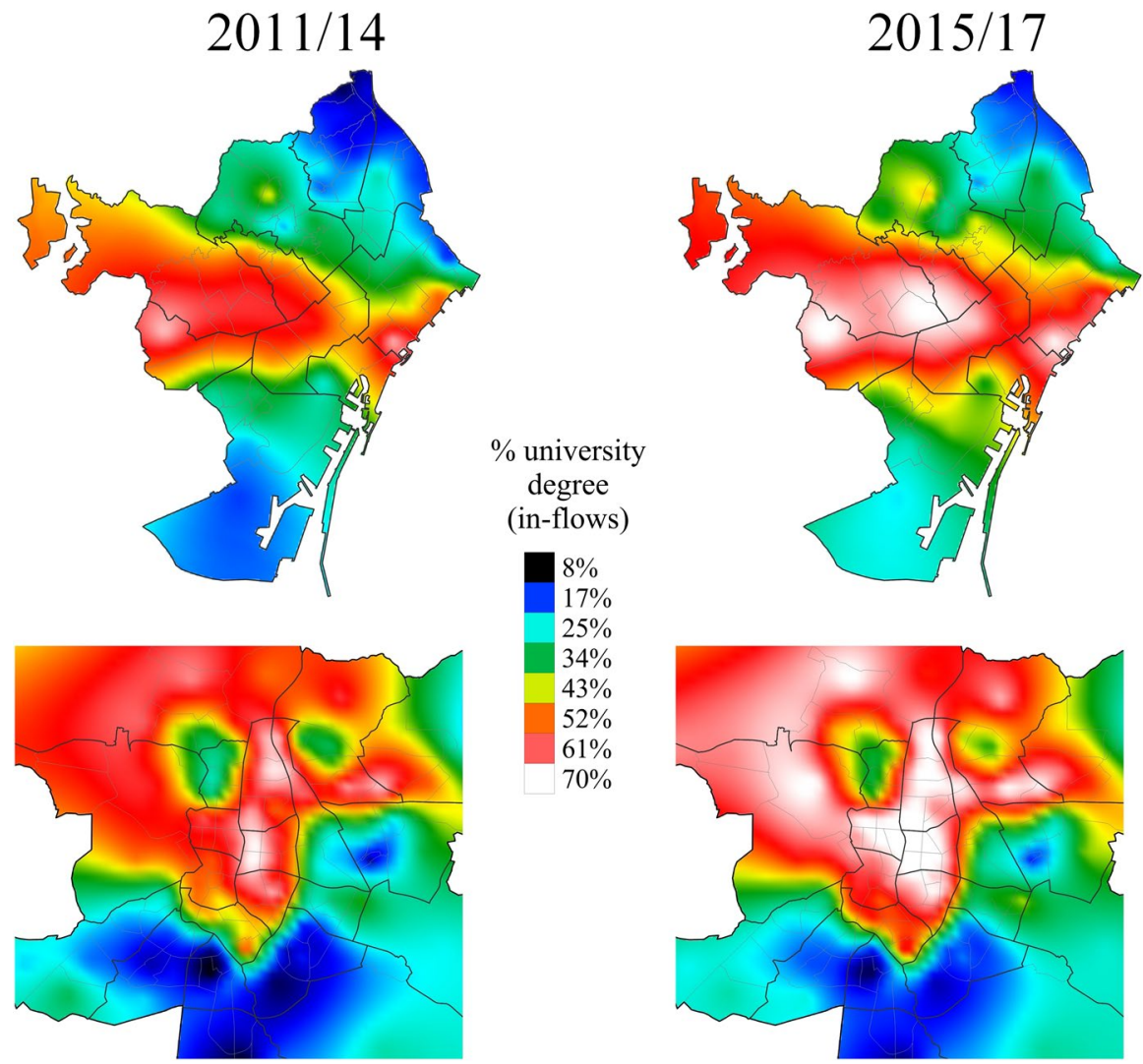

Fig. 8 Percentage of university-educated people related to the overall entry to each neighborhood. Population > 25 y.o., 2011-2017. Source. Own elaboration. In-flows and dwelling changes within the municipality (not including movements within the neighborhood) from the Population Register. Barcelona and Madrid city councils. Kriging interpolation 

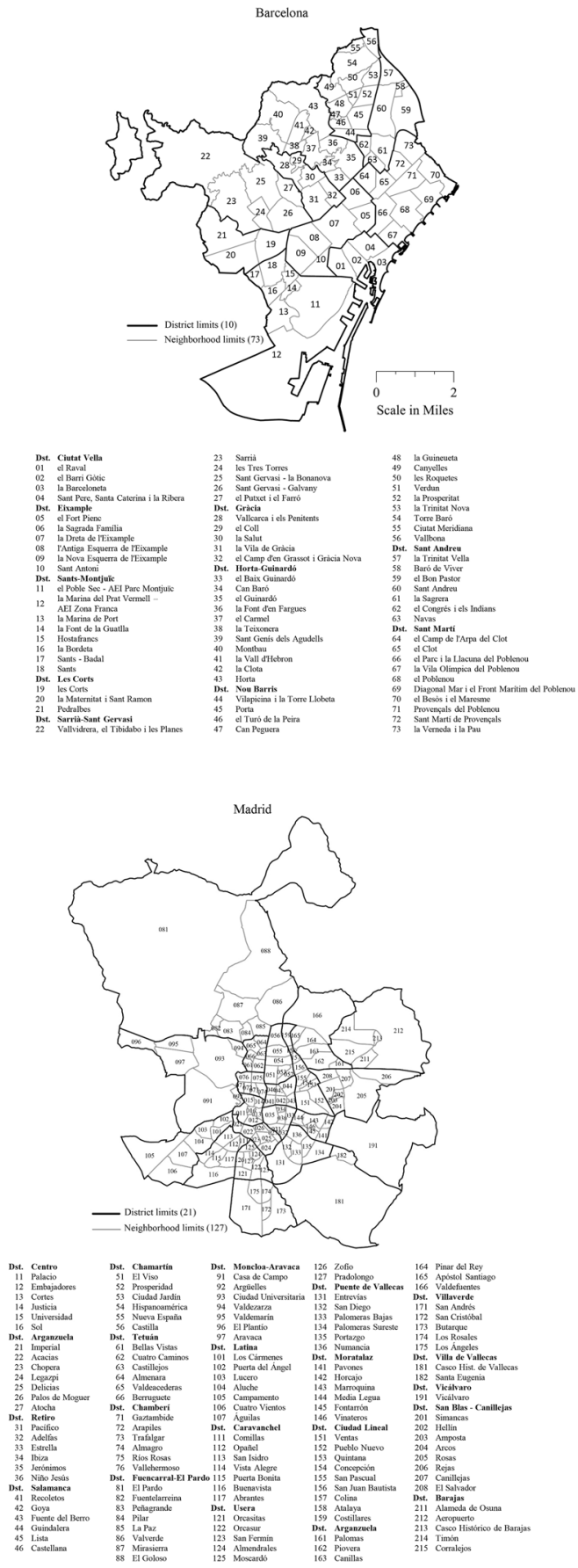
Publisher's Note Springer Nature remains neutral with regard to jurisdictional claims in published maps and institutional affiliations. 